\title{
A Comparison of Subscription and Open Access Journals in Construction Management and Related Fields
}

\author{
Bo-Christer Bjork, (Hanken School of Economics, Finland)
}

\begin{abstract}
The Internet has profoundly changed the technical infrastructure for the publishing of scientific peer reviewed journals. The traditional business model of selling the content to subscribers is increasingly being challenged by Open Access (OA) journals, which are either run at low cost by voluntary academics or which sell dissemination services to authors. In addition authors in many fields are taking advantage of the legal possibilities of uploading free manuscript versions to institutional or subject-based repositories, in order to increase readership and impact. This study looks closer at the current publishing situation in construction management and related fields and compares empirical data about $17 \mathrm{OA}$ journals and 16 traditional subscription journals. Of the articles published in 2011 in the subscription journals only $9 \%$ could be found as OA copies. The overall OA availability (including articles in OA journals) was $14 \%$ for Construction Management and Economics and $29 \%$ for construction IT scholarship. The study also compared the scientific quality of OA journals to subscription journals using a number of citation indexes. Four of the OA journals are approaching the citation levels (using Scopus data) of the average subscription journals. OA journals are outperforming subscription journals by almost a year in speed of publication.
\end{abstract}

Keywords: Scholarly publishing, Internet, Open Access, Business model

\section{Introduction}

The emergence of the Internet has profoundly changed the way we do business in many industries as well as our everyday social life. Among the most affected industries are those in which the product can be digitalized and thus multiplied and disseminated at almost zero marginal cost. All media industries, including the publishing of peer reviewed scholarly journals, belong to this category. Scientific publishing differs from the other branches of media, such as news, films, music and literature, in that the interest of the stakeholders funding and producing the content is not in revenue from the sales of the content but in maximizing the dissemination and impact on other researchers, on innovations and in the end public welfare. Nevertheless the publishers of scientific journals have been slow in adapting their business models to take full advantage of the opportunities offered by the Internet. Around the turn of the millennium, all major publishers started to publish electronic versions of their journal articles in parallel with the printed issues, as well as market electronic licenses to large bundles of titles ("big deals"), but the fundamental business model of selling access to the content to subscribers remained the norm. The novel idea of Open Access and seeing journals as service providers to the authors was initially embraced by individual scholars or groups of scholars setting up journals run on a volunteer basis and later by companies funding the operations by charging the authors for publishing, not by the established publishers.

Open Access (OA) means that the full text of the articles is accessible with no charges and access restrictions to anybody with an Internet connection. In the ideal OA scenario any reference in a scientific publication would be just one mouse-click away. There are many arguments for Open Access, but the most fundamental is that OA maximizes the impact of research on science, technology and society, by providing more access and readership than 
the restricted subscription model. Considering the huge public expenditure on research globally, the subscription revenue of an estimated 8 billion USD to the publishers of around 25000 peer-reviewed journals (Ware and Mabe 2009), which would have to be recuperated by other means in fully Open Access scenario, is next to nothing.

Why has the industry been so slow in changing its business model if $O A$ is as attractive as it seems. The basic reason is to be found in the high profit levels of the major publishers in a very oligopolistic market. Elsevier made a profit of 724 million GBP on revenues of 2 billion in 2010 , a margin of $36 \%$ (Economist 2012), and many leading scientific societies have built up big publishing branches that are dependent on subscription revenue. Such publishers understandably perceive no need to change a very comfortable status quo. The situation is further "cemented" by the virtual monopoly of ISI's citation indexing service and the impact factors it publishes for a restricted class of mainly older established journals, which has contributed to very high barriers to entry in this market.

The pressure for OA has thus come from outside the core group of established publishers and increasingly also from research funders like the National Institute of Health in the USA, the single biggest funder of medical research in the world. Publishers have reacted by antiOA lobbying and recently tried to introduce legislation in the US forbidding public research funders from requiring open access to the research results of their grantees. Due to widespread opposition from the academic world this initiative failed (Howard 2012).

\section{Gold and Green OA}

Open access can be achieved in a number of ways. Firstly the publisher can make the primary publishing site or parts of it openly accessible. Full Open Access where all articles are immediately free is often called "Gold" Open Access. This can be achieved using a variety of business models. The journal can be published only electronically and funded either with only voluntary labor, grants, using Open Source software etc, or by requiring the authors to pay for the publishing service in the form of Article Processing Charges (APCs). A recent empirical study shows that APCs fall in a wide range between 20 and 3000 USD, the average across some 100,000 articles published in 2010 being around 900 USD (Solomon and Björk 2012). The charges are typically highest in biomedicine journals, due to the better funding opportunities of the authors, and society journals and journals from the developing countries tend to have the lowest charges.

Another variant is where established journals, often society ones, have made the electronic version of the journals free while still getting subscription income from the printed version. Alternatively journals can open up the e-version with a delay so that readers requiring immediate access pay a subscription. A further variant is where subscription journals offer authors the possibility to open up their individual articles in otherwise subscription journals against a payment (hybrid OA). There are over 4000 journals allowing this, but the high price of usually around 3000 USD has resulted in a very low uptake of only around $1-2 \%$ of eligible articles (Dallmeier-Tiessen 2010).

From a legal perspective there are two flavors to Open access publishing, Gratis OA and Libre OA. Gratis OA means just the technical barrier free accessibility, in Libre OA the usage and re-use rights have been precisely defined, often via the use of Creative Commons (CC) licences attached to the journals and articles. Libre OA is particularly important is such sciences where journal articles and related data sets can be harvested to build aggregated data collections or new services.

There are currently around 7600 journals registered in the Directory of Open Access Journals (DOAJ 2012), publishing an estimated 340,000 articles in 2011. In terms of the global number of articles, the OA share is currently around $10 \%$, and the volume is increasing by around $30 \%$ per year (Laakso et al 2011).

Bjork, B (2012) 'A comparison of subscription and open access journals in construction management and related fields', Australasian Journal of Construction Economics and Building, 12 (2) 27-42 
The second route to disseminate the results openly is for the authors to make electronic copies of some version of the article manuscript available on a suitable web site ("green OA"). The three main options are on the author's own or his department's web pages, usually linked to his CV, in the institutional eprint repository of his university or in a subjectbased repository for the research area in question. Only a minority of universities have repositories and subject-based repositories have become popular only in some research areas (i.e. high-energy physics and biomedicine). The copy which is posted can range from a copy of the manuscript as initially submitted to the exact published pdf-file, the most common one being the manuscript version as accepted for publishing, but without the final copyediting and layout of the publisher. This is something a majority of publishers allow in their copyright agreement with the authors (The Sherpa/Romeo website is a good source to find out about the policies of individual publishers or journals, Sherpa/Romeo 2012). In practice many academics post clearly illegal exact copies of the published articles.

The global share of articles for which green copies can be found is estimated to be around 12-15\% (Björk et al 2010, Gargouri et al 2010 ). The share is much higher in certain disciplines like High-Energy Physics and Medicine, and for authors from universities, which require their faculty to post green copies.

\section{The OA situation in Civil Engineering Research}

Open Access has not yet been widely embraced by civil engineering researchers. There were until the last couple of years only a few OA journals in construction, none of which yet indexed by Web of Science. The field lacks a subject-based repository of its own and only a small minority of researchers has access to institutional repositories. Unlike fields such as biomedicine, the funders of the research haven't yet started requiring OA. Recently the situation has started to change due to the fact that a number of commercial OA publishers have launched journals also in civil engineering and keep spamming academics with requests to join the editorial boards of and to submit papers to these author charge funded journals. This has created some confusion among academics due to the apparent dubious quality of many of these journals and also triggered a recent debate on the CNBR mailing list (CNBR 2012).

The aim of this study has consequently been to shed some light on the current situation of scholarship in civil engineering, in particular in construction management and economics as well as in IT in construction. The focus has been on OA issues, but the general quality in terms of citation rates of the journals has also been included, since the thrush of the critique against OA publishing has been that such journals are of lower quality and put the whole peer review system in peril. With the exception of some parameters, such as the acceptance rates of journals, a lot of the information could be extracted from the web sites of the journals as well from some databases like Journal Citation Reports (JCR), Google Scholar and the Directory of Open Access Journals (DOAJ). For some aspects synthesizing the information was relatively easy, for others time-consuming.

\section{Journals included in the Study}

All in all 33 journals were studied, 17 OA journals, 16 subscription journals. Originally there were 16 of both categories but the author became aware of the recently founded International Journal of Construction Supply Chain Management at a late stage of manuscript preparation and added it. All relevant journals specialized in either construction management and economics or the use of IT in construction were included. In addition some general civil engineering titles with broad scope were included in the list of OA journals, in order to demonstrate better the spectrum of open access journals and publishers. Sources that helped determine titles of interest included the list of $\mathrm{CIB}^{1}$ encouraged and endorsed

\footnotetext{
${ }^{1}$ International Council for Research and Innovation in Building and Construction

Bjork, B (2012) 'A comparison of subscription and open access journals in construction management and related fields', Australasian Journal of Construction Economics and Building, 12 (2) 27-42
} 
journals, JCR rankings of journals in "Engineering, Civil", the Directory of Open Access Journals. The journals and some basic data about them are listed in table 1.

\begin{tabular}{|c|c|c|c|c|c|c|c|c|}
\hline \multirow{4}{*}{$\begin{array}{l}\text { Name } \\
\text { OA journals: } \\
\end{array}$} & \multicolumn{2}{|c|}{ Founded } & \multicolumn{5}{|c|}{ Type of publish، Publisher } & \multirow[t]{3}{*}{ Country } \\
\hline & & \multirow{3}{*}{$\begin{array}{l}\text { OA } \\
\text { from }\end{array}$} & \multicolumn{4}{|c|}{ Commercial } & & \\
\hline & & & & \multicolumn{3}{|c|}{ Society } & & \\
\hline & & & & & \multicolumn{3}{|c|}{ University } & \\
\hline Journal of the South African Institution of Civil Engineering & 1993 & 2010 & & $\sqrt{ }$ & & & S. A. Institution of Civil Eng.. & South Africa \\
\hline Electronic Journal of Structural Engineering & 2001 & 2001 & & & & $\sqrt{ }$ & EJSE & Australia \\
\hline Australasian Journal of Construction Economics and Building & 2001 & 2010 & & & $\sqrt{ }$ & & Uni. of Technology Sydney & Australia \\
\hline International Journal of Civil Engineering & 2003 & 2006 & & & $\sqrt{ }$ & & Iran Uni. of Scie. and Techno. & Iran \\
\hline Lean Construction Journal & 2004 & 2004 & & & & $\sqrt{ }$ & Lean Construction Insititute & USA \\
\hline The Open Civil Engineering Journal & 2007 & 2007 & $\sqrt{ }$ & & & & Bentham & U.A.E. \\
\hline International Journal of Civil and Structural Engineering & 2010 & 2010 & & $\sqrt{ }$ & & & Integrated Publishing Ass. & India \\
\hline Journal of Civil Engineering and Construction Technology & 2010 & 2010 & $\sqrt{ }$ & & & & Academic Journals & Nigeria \\
\hline ISRN Civil Engineering & 2011 & 2011 & $\sqrt{ }$ & & & & Hindawi & Egypt \\
\hline Journal of Civil and Environmental Engineering & 2011 & 2011 & $\sqrt{ }$ & & & & OMICS & Egypt \\
\hline Int. Journal of Construction Supply Chain Management & 2011 & 2011 & & & & $\sqrt{ }$ & IJCSCM & New Zealand \\
\hline Buildings & 2011 & 2011 & $\sqrt{ }$ & & & & MDPI & Switzerland \\
\hline Journal of Computing in Civil Engineering & 1986 & & & $\sqrt{ }$ & & & ASCE & USA \\
\hline Computer-aided civil and infrastructure engineering & 1986 & & $\sqrt{ }$ & & & & Wiley \& Blackwell & USA \\
\hline Advanced Engineering Informatics & 1987 & & $\sqrt{ }$ & & & & Elsevier & Netherlands \\
\hline Automation in Construction & 1992 & & $\sqrt{ }$ & & & & Elsevier & Netherlands \\
\hline Engineering, Construction and Architectural Management & 1994 & & $\sqrt{ }$ & & & & Emerald & UK \\
\hline Journal of Civil Engineering and Management & 1995 & & $\sqrt{ }$ & & & & Taylor \& Francis & UK \\
\hline Journal of Architectural Engineering & 1995 & & & $\sqrt{ }$ & & & ASCE & USA \\
\hline Construction Innovation & 2001 & & $\sqrt{ }$ & & & & Emerald & UK \\
\hline International Journal of Construction Management & 2001 & & & & $\sqrt{ }$ & & Chinese Res. I. of Con. Man. & China \\
\hline Journal of Engineering Design and Technology & 2003 & & $\sqrt{ }$ & & & & Emerald & UK \\
\hline Architectural Engineering and Design Management & 2005 & & $\sqrt{ }$ & & & & Taylor \& Francis & UK \\
\hline
\end{tabular}

Table 1 The studied OA and subscription journals

In the table the publishers of the journals have been classified into four categories, commercial publishers, scientific societies, universities/research institutes and independent journals run be groups of academics. In some OA cases the classifications are a matter of choice. Journal of Information Technology in Construction for instance is formally published by CIB but in practice by a group of collaborating academics. The journals are listed in age order, the oldest ones first. Three publishers; Taylor \& Francis, Emerald and the American Society for Civil Engineers, ASCE, dominate the subscription market. Commercial publishers have entered the OA market rather late. In the case of two of the commercial OA publishers (Bentham and Academic Journals) it was difficult to find out about the publisher's home country from the web site, but there are indications that the United Arab Emirates is the site of Bentham and Nigeria or Kenya of Academic journals (Beall 2011). 
Table 2 shows the pricing policies of the journals. All prices are in US Dollars. For the Open Access journals the price indicated is the article processing charge (APC) that authors have to pay. Journal of Civil and Environmental Engineering has a three-tier price based on the country of origin of the corresponding author, with the lowest price level for developing country authors. Buildings has an introductory offer of no APC for submissions in 2012, but can be expected to levy an APC later on, based on pricing info for some other OA journals from the same publisher.

\begin{tabular}{|c|c|c|c|}
\hline Pricing and information & & & \\
\hline & Article & & \\
\hline & processinc & & \\
\hline OA journals: & charge & & \\
\hline Journal of the South African Institution of Civil Engineering & Free & & \\
\hline Journal of Construction in Developing Countries & Free & & \\
\hline Journal of Information Technology in Construction & Free & & \\
\hline Electronic Journal of Structural Engineering & Free & & \\
\hline Australasian Journal of Construction Economics and Building & Free & & \\
\hline International Journal of Civil Engineering & Free & & \\
\hline Lean Construction Journal & Free & & \\
\hline The Open Civil Engineering Journal & 800 & & \\
\hline the Open Construction and Building Technology Journal & 800 & & \\
\hline Advances in Civil Engineering & 600 & & \\
\hline International Journal of Advanced Structural Engineering & Free & & \\
\hline International Journal of Civil and Structural Engineering & Free & & \\
\hline Journal of Civil Engineering and Construction Technology & 550 & & \\
\hline ISRN Civil Engineering & 500 & & \\
\hline Journal of Civil and Environmental Engineering & $900-1800$ & & \\
\hline Int. Journal of Construction Supply Chain Management & Free & & \\
\hline Buildings & 0 & & \\
\hline & Article OA & Institutional & Pay per \\
\hline & Option & Subscription & view \\
\hline Subscription Journals: & (hybrid) & & \\
\hline Journal of Construction Engineering \& Management & & 908 & 30 \\
\hline Building Research and Information & & 1944 & 27 \\
\hline Construction Management and Economics & 3250 & 3521 & 27 \\
\hline Facilities & & 10589 & 27 \\
\hline Journal of Management in Engineering & & 305 & 30 \\
\hline Journal of Computing in Civil Engineering & & 490 & 30 \\
\hline Computer-aided civil and infrastructure engineering & & 1316 & $?$ \\
\hline Advanced Engineering Informatics & 3000 & 1424 & 39 \\
\hline Automation in Construction & 3000 & 964 & 39 \\
\hline Engineering, Construction and Architectural Management & & 2229 & 25 \\
\hline Journal of Civil Engineering and Management & 3250 & 712 & 32 \\
\hline Journal of Architectural Engineering & & 317 & 30 \\
\hline Construction Innovation & & 599 & 25 \\
\hline International Journal of Construction Management & & 330 & ? \\
\hline Journal of Engineering Design and Technology & & 419 & 25 \\
\hline Architectural Engineering and Design Management & 3250 & 542 & 32 \\
\hline
\end{tabular}

Table 2 Pricing information for the studied journals

Bjork, B (2012) 'A comparison of subscription and open access journals in construction management and related fields', Australasian Journal of Construction Economics and Building, 12 (2) 27-42 
For the subscription journals the hybrid OA charge has been shown for those journals that propose this option for authors wishing "to open" up their individual article. The Institutional subscription price, usually for electronic only subscriptions are shown. In the case of Emerald it was almost impossible to find pricing information, but a price list for 2009 with a wide ranges of prices was found on the web (Emerald 2008). The prices for two of the journals seem believable but the prices of Engineering, Construction and Architectural Management and in particular Facilities do not look credible. It seems that Emerald prefers to have potential customers contact them by email and then negotiate prices on case-bycase basis.

\begin{tabular}{|c|c|c|c|c|c|c|}
\hline & Articles & & & & & \\
\hline & published & & & & & \\
\hline OA journals: & 2011 & & & & & \\
\hline & & & & & & \\
\hline & & & & & & \\
\hline Journal of the South African Institution of Civil Engineering & 7 & & & & & \\
\hline Journal of Information Technology in Construction & 44 & & & & & \\
\hline Electronic Journal of Structural Engineering & 8 & & & & & \\
\hline Australasian Journal of Construction Economics and Building & 21 & & & & & \\
\hline International Journal of Civil Engineering & 35 & & & & & \\
\hline Lean Construction Journal & 9 & & & & & \\
\hline International Journal of Advanced Structural Engineering & 0 & & & & & \\
\hline International Journal of Civil and Structural Engineering & 86 & & & & & \\
\hline Journal of Civil Engineering and Construction Technology & 18 & & & & & \\
\hline ISRN Civil Engineering & 17 & & & & & \\
\hline Journal of Civil and Environmental Engineering & 5 & & & & & \\
\hline Int. Journal of Construction Supply Chain Management & 4 & & & & & \\
\hline \multirow[t]{3}{*}{ Buildings } & 1 & & & & & \\
\hline & 325 & & & & & \\
\hline & & OA posting & OA & $\mathrm{OA}$ & OA \% 10 & OA \% \\
\hline Facilities & 38 & 0 & 3 & 8 & 10 & 0 \\
\hline Journal of Management in Engineering & 28 & 0 & 3 & 11 & 0 & 4 \\
\hline Journal of Computing in Civil Engineering & 49 & 0 & 5 & 10 & 30 & 12 \\
\hline Computer-aided civil and infrastructure engineering & 43 & 12 & 6 & 14 & 40 & 2 \\
\hline Advanced Engineering Informatics & 67 & 0 & 9 & 13 & 80 & 8 \\
\hline Automation in Construction & 112 & 0 & 26 & 23 & 70 & 5 \\
\hline Engineering, Construction and Architectural Management & 36 & 0 & 5 & 14 & 10 & 0 \\
\hline Journal of Civil Engineering and Management & 57 & 12 & 0 & 0 & 80 & 1 \\
\hline Journal of Architectural Engineering & 16 & 0 & 3 & 19 & 20 & 0 \\
\hline Construction Innovation & 27 & 0 & 2 & 7 & 20 & 0 \\
\hline International Journal of Construction Management & 20 & $?$ & 0 & 0 & 10 & 0 \\
\hline Journal of Engineering Design and Technology & 21 & 0 & 0 & 0 & 10 & 0 \\
\hline \multirow[t]{2}{*}{ Architectural Engineering and Design Management } & 19 & 12 & 0 & 0 & 30 & 0 \\
\hline & 787 & & 73 & 9 & & 72 \\
\hline
\end{tabular}

Table 3 Article volumes and share of subscription journal article openly available

The institutional subscription prices should only be seen as indicative since most subscriptions are sold as part of bigger package deals and since there may be discounts for some subscribers. A key lesson seems to be that there seems to be little correlation

Bjork, B (2012) 'A comparison of subscription and open access journals in construction management and related fields', Australasian Journal of Construction Economics and Building, 12 (2) 27-42 
between journal quality and volume with the price. Earlier studies have shown that society journals tend to be much cheaper than equivalent commercial journals (European Commission 2006). The pay-per-view prices for access to individual articles are in much more narrow range, 25-39 USD. Interestingly Emerald also offers articles to be rented for 24 hours in non-printable versions for USD 3.99.

The first column in Table 3 shows information about the number of articles published in 2011. Understandably some of the OA journals, especially the recently founded ones have low publication volumes. Many of the subscription journals are quarterly journals with a volume of around 20-30 articles per year, but there are a couple of journals publishing more than one hundred articles per annum.

The second column ("OA posting allowed") indicates the copyright restrictions of the journals. None of the journals allow the posting of the PDFs as published. In the column the restrictions concerning the so-called personal versions, the manuscripts as accepted for publishing, are indicated. A zero means that authors can post this version immediately, 12 that this can be done one year after publishing. For the International Journal of Construction Management it wasn't possible to find such information.

Columns 3 and 4 indicate the number and percentage of green OA copies found using Google Scholar (GS) for the 2011 articles. The advanced search facility in GS makes it possible to search for articles published in a named journal in a given year. Openly available full text copies are clearly shown in a separate column. All indentified copies were downloaded, studied and classified according to the location of the copy and the type of version. Of the copies found it turned out that around a third were clearly illegal copies (downloaded published versions or proof versions the authors had received from the publishers). Very few copies fulfilled all the stipulations in the copyright agreements with the publisher in the sense of indicating the status of the copy as well as the definitive published version. An example of how this should be done is shown in figure 1. In practice the likelihood of publishers following up on the compliance to these rules not to mention trying to enforce them by sanctions is extremely low.

\section{QUT}

Queensland University of Technology

Brisbane Australia

This is the author's version of a work that was submitted/accepted for publication in the following source:

Bakti, Erman Surya, Abdul Majid, Muhd Zaimi Bin, Zin, Zin, Rosli Mohamad, \& Trigunarsyah, Bambang (2011) Constructability improvement in sea water intake structure. Engineering, Construction and Architectural Management, 18(6). (In Press)

This file was downloaded from: http://eprints .qut.edu.au/44033/

\section{(C) Copyright 2011 Emerald Group Publishing}

Notice: Changes introduced as a result of publishing processes such as copy-editing and formatting may not be reflected in this document. For a definitive version of this work, please refer to the published source:

Figure 1 An example of how a green copy should ideally be posted, in this case in an institutional repository
An interesting observation is that authors in the construction IT journals seem to be more active in posting $O A$ copies of their articles. The OA availability of highly cited articles from any year was additionally checked in two ways, for the ten most cited articles in each journal (column 5) and for all articles that had more than 100 citations in GS. For most journals highly cited articles were more commonly available than 2011 articles in general and the average availability of articles with $>100$ citations was $40 \%$. 


\section{Quality Labels and Citation Metrics}

Table 4 contains data related to the quality and the citation rates of the journals. CIB encouraged journals are marked with an $\sqrt{ }$, including all the subscription journals except the one's published by the ASCE and Advances in Engineering Informatics, as well as three of the OA journals. Most of the OA journals are listed in the Directory of Open Access journals, which applies some quality checks for inclusion. The criteria for the publisher being accepted as a member in the Open Access Scholarly Publishers' Association OASPA are more stringent, and include criteria related to the trustworthiness and transparency of the peer review process.

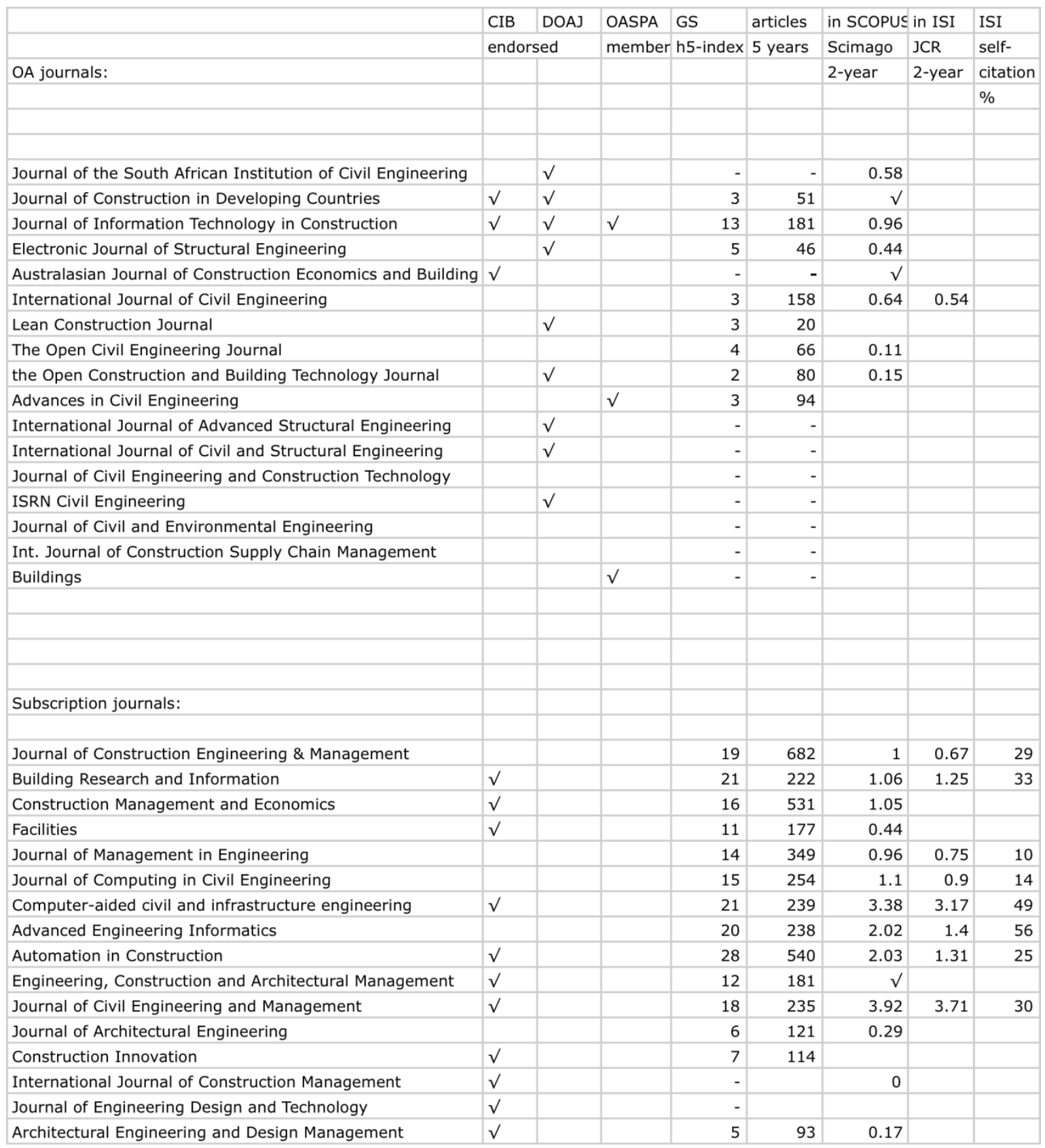

Table 4 Quality assurance and performance

The only practical way to empirically estimate the scientific quality or impact of a journal is by counting citations per published article. Three sources for citations have been used; Web of Science, Scopus and Google Scholar. The best-known statistics for this purpose are provided by the ISI for those journals indexed in its Web of Science in the Journal Citation

Bjork, B (2012) 'A comparison of subscription and open access journals in construction management and related fields', Australasian Journal of Construction Economics and Building, 12 (2) 27-42 
Reports. Since ISI is quite conservative in including new journals into this index only some of the journals in this study have so-called impact factors, of which the two-year impact factor is the best known.

The clearly higher JCR impact factors of some of the journals in this study should be regarded with some skepticism. Ideally the relative shares of different citing journals should reflect where the scholarship in the field is to be found. But in some cases the journal itself can provide a disproportionate share of the citations, thus improving the rating. Especially for journals with initially low average citation numbers the impact factors can dramatically rise from one year to the other as a result of a lot of citations in the journal itself or in other closely connected ISI-indexed publications. To highlight this the share of journal internal citations that contributed to the two-year impact factor in the 2010 Journal Citation reports was calculated and is shown in the last column of table 4. For most journals the shares varied between 10-33 \% but both Advanced Engineering Informatics with $56 \%$ and Computer-Aided Civil and Infrastructure Engineering with $49 \%$ had much higher rates.

An alternative to Journal Citation reports is offered by the similar citation metrics available from the openly accessible SCImago web site (SCImago 2012), which uses data from the Scopus citation index as a base. Scopus includes around $50 \%$ more journals and $20 \%$ more articles than ISI, and since there is a high correlation between its figures and the ISI impact factors it provides a better tool for comparisons. In our case it was possible to get Scopus two-year citation averages for 19 of the journals, compared to 9 impact factors from JCR.

A newcomer to the family of journal level metrics is the h5-index, which Google Scholar has started to publish in April 2012. This index counts the number of citations in Google Scholar to articles published in the most recent five year in a particular journal, and calculates the highest number where there are at least $x$ articles with at least $x$ citations. It is the same metric (Hirsch index) that has been proposed for authors, but here applied to journals. The h5-index can be regarded as a better measure of overall journal performance compared to the traditional impact factor, in particular for smaller volume journals were one or two highly cited articles can raise the average impact factor a lot. The only drawback is that for journals of equal average level of citations this index tends to grow higher with the number of published articles. Not all the journals in this study could directly be found in the Google Scholar reports, but for such journals that were older than five years it was easy to handcount the citations in the general GS search engine and construct the figure manually.

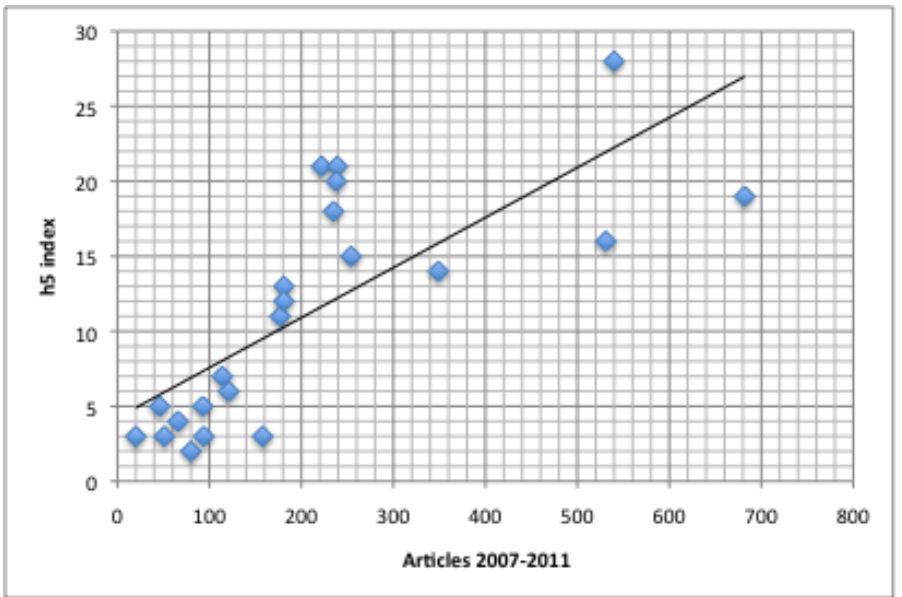

Figure 2 H5 index for citations in Google Scholar. The journals can be identified by comparing the $x-$ and $y$-values with table 4 . Journals above the line perform above average
Of these three sources of citations Google Scholar is the most useful for this study in reflecting research impact, since comparable data can be obtained for almost all the journals in this study (except the newly started ones). Google scholar also catches citations in for instance conference proceedings, which in our field are an important part of the scholarship

The citation data for the journals are shown in the table 4 above. If a figure is not given in the table for some journal the symbol "-" denotes that the figure isn't relevant (the journal is too young to have data)

Bjork, B (2012) 'A comparison of subscription and open access journals in construction management and related fields', Australasian Journal of Construction Economics and Building, 12 (2) 27-42 
and " $\sqrt{ }$ " that the journal has been accepted for indexing in the data base but that impact factors cannot yet be calculated. An interesting way to illustrate the h5-index is in the form of a graph with the index on the vertical axis and the number of published articles on the horizontal axis (Figure 2). The journals situated above the line can be regarded as having better than average quality. It is easy to identify the different journals by comparing with the values in Table 4.

\section{Acceptance Rates and Time from Submission to Publication}

In addition to the scientific quality or prestige of a journal authors are usually, prior to submitting their manuscripts to it, also very interested in finding out the acceptance rate and the expected time from submission to publication. The only way to find information on the acceptance rate is if the publisher in question has put this information on the web. The OA publisher Hindawi does this regularly for its journals. In other cases it was possible via a Google search ("name of journal" + "acceptance rate") to find figures quoted in for instance editorials. Table below 5 includes some data found this way.

\begin{tabular}{|l|c|l|}
\hline \multicolumn{1}{|c|}{ Journal } & Acceptance Rate & \multicolumn{1}{c|}{ Source } \\
\hline Advances in Civil Engineering & 33 & Hindawi 2012 \\
\hline $\begin{array}{l}\text { Australasian Journal of Con. Economics and } \\
\text { Building }\end{array}$ & 30 & Data from publisher \\
\hline $\begin{array}{l}\text { Computer-aided Civil end Infrastructure } \\
\text { Engineering }\end{array}$ & 35 & Easa \& Hoel 2008 \\
\hline Construction Management and Economics & 48 & CME 2010 \\
\hline Journal of Computing in Civil Engineering & 46 & Abudayyeh et al 2006 \\
\hline Journal of Information Technology in Construction & 36 & Data from publisher \\
\hline All 30 ASCE journals & 56 & Sinha 2004 \\
\hline
\end{tabular}

Table 5 Acceptance rates of some of the journals in the study

The differences are not that big, there is no journal that is characterized by a very selective review process. The acceptance rates might be higher for some of the recently launched APC funded OA journals which advertise very rapid lead times from submission to publication on their web sites.

Data about the lead times from submission to publication can be obtained in two ways. Firstly from statistics provided by the publisher or reports in earlier studies and secondly for those journals that publish submission dates of the individual articles by counting the lead times article by article (a rather painstaking process). Table 6 contains information on the lead times for some journals.

\begin{tabular}{|l|c|l|}
\hline \multicolumn{1}{|c|}{ Journal } & $\begin{array}{c}\text { Publication lead } \\
\text { time }\end{array}$ & \multicolumn{1}{|c|}{ Source } \\
\hline Advances in Civil Engineering & 6.7 & Hindawi 2010 \\
\hline Automation in Construction & 18.7 & Björk et al 2005 \\
\hline Construction Innovation & 18 & Björk at al 2005 \\
\hline Journal of Information Technology in Construction & 6.7 & Björk et al 2005 \\
\hline Open Civil Engineering Journal & 9.5 & $\begin{array}{l}\text { Counted from journal } \\
\text { web site }\end{array}$ \\
\hline
\end{tabular}

Table 6 Average lead times from submission to publication for some of the journals in the study

Of these the OA journals have much shorter times than the subscription ones. In addition to these the Australasian Journal of Construction Economics and Building has stated in

Bjork, B (2012) 'A comparison of subscription and open access journals in construction management and related fields', Australasian Journal of Construction Economics and Building, 12 (2) 27-42 
announcements that it strives to publish submissions within 6 months. International Journal of Civil and Structural Engineering, based in India, says on its web pages: "Rapid publication, your article will be online within 4 weeks of time after submission date". It was not, however, possible to check if this was true, but if it were, it would not make the journal a credible peer reviewed one. For journals of equal scientific integrity (meaning that the review process takes approximately the same time) the difference in speed between OA and traditional journals is largely due to the fact that subscription journals have a very fixed issue schedule and volume, and that it is in the editors' interest to keep a fairly sizeable buffer of publishing-ready papers waiting in line, in order to avoid possible shortages. In implicit recognition of this problem most traditional journals have nowadays started posting the electronic versions of the articles earlier than the actual publication in the paper version ("in press").

\section{Accessibility of the Subscription Journals to Scholars and Practitioners}

Since I'm working in a business school the portfolio of electronic subscription journals that our library provides is limited in its coverage of fields outside the core business management and economics disciplines. Of the 16 subscription journals included in this study I have full access to seven, access to articles published more than 12 months ago in the case of four journals and no access for the remaining five journals. All the journals with full or partial access are included in large e-licenses provided by the major publishers or aggregators (i.e. Elsevier SD Freedom Collection, EBSCOhost Business Source Complete).

This kind of situation if probably not uncommon for many researchers in our field. Those who are fortunate to work in the civil engineering departments of major universities in the leading industrialized countries might even have full immediate access to all the journals, but many researchers, in particular in the developing countries, not to mention practitioners all over the world, have much more limited access. It is not only the price of the subscriptions that is a barrier, it's also the transaction cost of setting up and paying subscriptions, in particular for single journals. An email sent to a number of former colleagues in Scandinavia confirmed this pattern; Two PhDs working in organizations funding construction research had no access at all. A researcher at a big research centre with several hundreds of researchers in civil engineering had full access to 10 and delayed access to 4 journals, another one at national research centre access to 7 out of 16 . Two researchers at major technical universities had immediate access to 14 out of the 16 journals.

The ease of access to the core journal literature in our field could easily be studied more systematically via a web survey sent out to members of professional societies in our field or email lists like CNBR, asking respondents about their paid access to the journals in question and whether they us pay-per-view services in case they don't have access. It would in particular be interesting to check the availability of the journals that CIB endorses to the researchers in its member organizations.

\section{Repositories for Green OA copies}

The only subject based repository in our field is the ITC Digital Library for construction IT research (ITC 2012) which was started in 2003 and is hosted at the University of Ljubljana. It partly uses the same software as the Journal of Information Technology in Construction. The bulk of the content consists of the papers presented at the CIB Working Commission W78 conferences since 1984, but otherwise the service has not become popular as a place where researchers post manuscript copies of their journal papers.

Some of the universities of researchers in our field can use institutional repositories, for instance provided by Loughborough University and Queensland University of Technology (for a list of such repositories see either OpenDOAR 2012 or ROAR 2012). In some cases this technical infrastructure is also supported by university policies requiring faculty to deposit copies of their manuscripts for journal articles, whenever legally possible (Bath,

Bjork, B (2012) 'A comparison of subscription and open access journals in construction management and related fields', Australasian Journal of Construction Economics and Building, 12 (2) 27-42 
Salford, Reading, QUT). A list of such mandates is available at (ROARMAP 2012) or (Sherpa/Juliet 2012).

\section{Conclusions}

The journal scenery in construction management as well as construction IT can be characterized as rather "flat" in the sense of several journals of relatively equal scientific quality competing for manuscripts. This is in contrast with some other scientific fields where there is a single top journal with very rigorous peer review and low acceptance rate and below that a clear hierarchy of journals, in terms of quality and prestige. Most journals in our field have an acceptance rate in the range $30-50 \%$ and given that a share of papers of very low quality or with the wrong topic are desk rejected by the editors all reasonable papers are likely to be accepted, if not in the first journal submitted to, then at least in the second. The journals are pretty much run by the editors-in-chief, who in many cases have been in charge of the journals for over a decade, and there is no rotation at regular intervals, a practice common for instance in top management journals. Editorial boards are rarely consulted for advice and have often remained almost the same for decades, since the journals were founded. There is strong overlap in the composition of these editorial boards and many academics in our field sit on the editorial boards of several of these journals.

Since only one of the OA journals is indexed in ISI it is difficult to compare the quality with subscription ones using that data. Scopus and Google Scholar offer better possibilities for this. The five OA journals for which Scopus data is available have two year citation counts in the range of $0.41-0.96$. Although there are four subscription journals with clearly higher averages, the remaining twelve fit in the range $0.17-1.10$. It can be noted that a recent study has shown that Scopus indexed OA journals overall receive around two thirds as many citations as subscription ones (Björk and Solomon 2012). The global average is lowered by the many old journals that have made the e-version free. When comparing only journals founded after 2001 the difference more or less disappears. Unfortunately the very low grade journals from a handful of publishers frequently spamming academics with emails is giving OA a bad image, but their publication volumes are so low that their overall share of published OA articles is only around $2-3 \%$.

In the old printed-only environment journals that were not successful in attracting subscribers went out of business after a few years. In the new situation with electronic delivery as the main channel journals published by major publishers are rarely cancelled. This is partly because university libraries concentrate their subscription budgets to huge elicenses with a few publishers, thus obscuring the marginal revenue of individual titles and partly because the marginal cost of keeping journals running is relatively low due to the economies of scale in using the workflow and production systems of a publisher. The trend thus seems to be that only subscription journals published by major publishers have the "staying power" to survive using this business model.

The situation can best be illustrated by the development of a number of journals from small publishers. Construction Innovation originated as the International Journal of Construction Information Technology, a journal published by the University of Salford between 1992 and 2000. The journal changed name to Construction Innovation as well as focus when Arnold Publishers took over in 2001. In 2006 Emerald acquired the journal. A competing journal was Computer Integrated Design and Construction published by Millpress from 1999 to 2001 and then by the Institution of Structural Engineers from 2003 to 2004 under the title International Journal of IT in Architecture, Engineering and Construction (IT-AEC). Due to an insufficient number of subscribers the journal was merged with the Open Access Journal of Information Technology in Construction (ITcon) in 2005.

ISI started to index several journals published by the Vilnius Gediminas Technical University (Lithuania) around 2008, as part of a campaign to index more regional journals from

Bjork, B (2012) 'A comparison of subscription and open access journals in construction management and related fields', Australasian Journal of Construction Economics and Building, 12 (2) 27-42 
countries outside the leading Anglo-Saxon ones. In 2010 Tailor \& Francis signed a copublication agreement with the university including several of the journals that were due to receive impact factors in 2011 (ATG 2010]. The Journal of Civil Engineering and Management which had formerly been known as Statyba - Civil Engineering, was one of these journals which achieved very high impact factors near the top ranking in their respective disciplines in the first year of receiving an IF.

All the OA journals started before 2007 are published either by scientific associations or by independent groups of academics. Some have been OA from the start (for instance Journal of Information Technology in Construction and Electronic Journal of Structural Engineering) while others have started out as print journals but later converted to OA. The costs of going OA have been kept very low by using third part free OA portals like Scielo (Journal of the South African Institution of Civil Engineering) or by using Open Source software for running the journal (Australasian Journal of Construction Management and Building).

After 2007 a number of commercial publishers funding their journals with article procession charges have entered the market. A rather curious journal is the International Journal of Advanced Structural Engineering. It is part of a group of nine open access journal published by Springer in close co-operation with the Islamic Azad University, South Tehran branch. The university provides funds to cover all costs of publication in these journals, including the Article Processing Charges (APC's) for all authors, which Springer charges for its other OA journals.

OA journals rarely go out of business, since the cost of running them are very low. They can more easily than subscription journals survive bad years with few published articles. The only OA journal in civil engineering or a related field to have disappeared from the scene so far is the International Journal of Design Computing, published by the Faculty of Architecture of the University of Sydney between 1997 and 2004. The journal encouraged interactive media features in articles but only a handful of articles were published per year. Fortunately the National Library of Australia has ensured the long-term preservation of the articles.

Only five of the OA journals are specialized in construction management and economics or construction IT. If the article volumes of these in 2011 are compared with the number of articles in the thirteen corresponding subscription journals, the overall gold OA percentage would be $10.0 \%$. The green OA share of the articles in the 13 journals was $10.7 \%$. These figures are well in line with global averages for articles published in 2008 reported in Björk et al (2010).

Of particular interest is that the overall OA availability of the articles was $14 \%$ for construction Management end Economics and $29 \%$ for construction IT. These figures can be compared to $21 \%$ for Information Systems research (Björk, Laakso and Welling 2011), $26 \%$ for Library Information Systems (Way 2010) and $36 \%$ for Business and Management (Lyons and Booth 2011).

\section{Discussion}

The open access of construction management as well as construction IT journal literature could be enhanced with only a modest level of effort. The green route is the most direct. In almost all cases the authors could legally upload the manuscript copies as soon as they have been accepted for publishing and in the case of one publisher with a delay of one year. This should not take more than a couple of hours per article and is in the best interest of the authors as well as their institutions and funders. In many cases the employing universities already have suitable repositories and if not authors can put the copies on their home pages.

Unfortunately construction management lacks a suitable subject-based repository and the existing repository for construction IT is not much used. Setting up such a repository would

Bjork, B (2012) 'A comparison of subscription and open access journals in construction management and related fields', Australasian Journal of Construction Economics and Building, 12 (2) 27-42 
not be difficult to do, there are couple of widely used open source platforms available exactly for the purpose (D-space, E-prints). Such a platform could also become a very useful source for conference papers, in particular if the organizers would use it as the primary publishing platform.

Journal of Information Technology in Construction is well established as the primary Open Access alternative in construction IT field, and has proven that given the support of the research community it is possible to sustainably run a journal that does not need to charge the authors. There are three existing Open Access journals within the field of construction management, of which both Lean Construction Journal and International Journal of Construction Supply Chain Management have a rather narrow focus and the Australasian journal of Construction Management and Building a regional basis. Establishing a global CME journal with a broad scope using the Open Access business model would be a very valuable service to the research community. This could be done either based on the Open Source - Volunteer model or in partnership with a reputable OA publisher using article processing charges in the 500-900 USD range. Although major commercial publishers would probably be very interested in adding such a journal to their rapidly growing OA offering, the higher APCs that they tend to charge would be likely to deter submissions, at least in our field. The absolutely key issue in launching and sustaining such a journal would be the organization of the collective effort in such a way that a strong international team of editors and associate editors supported by an active editorial board would shape the peer review and other policies of the journal, and in engaging the research community in the field to submit good manuscripts and to review them.

\section{Acknowledgements}

The inspiration for the study presented in this article was a recent debate on the CNBR mailing list started by Peter Love's message (23.3. 2012) with the subject header "open Access: caution", in which colleagues were warned not to publish in open access journals. The motivation for his advice was the poor quality of some journals from commercial OA publishers that currently spam academics with emails asking them to submit papers and to join their editorial boards. I took part in the debate presenting some empirical facts about the prevalence and quality of $\mathrm{OA}$ in general, but it also arouse my interest in studying the current situation in our field more closely and to share the findings with my colleagues in an efficient openly accessible way.

\section{References}

Abbudayeh, O., Dibert-De Young, A., Rasdorf, W., Melhem, H. (2006) 'Research Publication Trends and Topics in Computing in Civil Engineering', Journal of Computing in Civil Engineering, 20 (1), 2-12

OA copy available from http://www.lib.ncsu.edu/resolver/1840.2/554

ATG (2010) Taylor \& Francis and VGTU Journals forge co-publishing partnership, 26.7.2010, Against the Grain, e-newsletter,

http://www.against-the-grain.com/2010/07/taylor-francis-and-vgtu-journals-forge-copublishing-partnership/

Beall, J. (2010) '"Predatory" Open Access Publishers', The Charleston Advisor, 15.2.2010, eprints.rclis.org/bitstream/10760/14576/1/predatory.pdf

Björk, B-C., Laakso, M. and Welling, P. (2011) 'Open Accessibility to Information Systems Research Articles', European Conference on Information Systems, ECIS 2011, Helsinki, Finland, OA copy available from

http://is2.Ise.ac.uk/asp/aspecis/20110153.pdf

Björk, B-C. and Solomon, D. (2012) 'Open Access versus subscription journals - A comparison of scientific impact', Submitted to BMC Medicine, April 2012

Bjork, B (2012) 'A comparison of subscription and open access journals in construction management and related fields', Australasian Journal of Construction Economics and Building, 12 (2) 27-42 
Björk, B-C., Turk, Ž, Holmström, J. (2005) 'The Scholarly Journal Re-engineered: A Case Study of an Open Access Journal in Construction IT',

Electronic Journal of Information Technology in Construction, 10, 349-371, http://www.itcon.org/

Björk, B-C., Welling P., Laakso, M., Majlender P., Hedlund T. and Gudnasson, G. (2010) 'Open access to the Scientific Journal Literature: Situation 2009', PLOS ONE, 5 (6). e11273. doi:10.1371/journal.pone.0011273

CME (2012) 'Construction Management and Economics: 1992-2008', Publisher's webpages, www.tandf.co.uk/Journals/pdf/announcements/rcme stats.pdf

CNBR (2012) Co-operative Network for Building Researchers, email discussion list, tech.groups.yahoo.com/group/cnbr-I/

Dallmeier-Tiessen, S., Goerner, B., Darby, R., Hyppoelae, J., Igo-Kemenes, P., Kahn, D., et al. (2010) 'Open Access Publishing - Models and Attributes, SOAP project report', Max Planck Society digital library, http://edoc.mpg.de/478647

DOAJ (2011) 'Directory of Open Access Journals', http://www.doaj.org/

Economist (2012) 'The price of information - Academics are starting to boycott a big publisher of journals', Feb 4th 2012, The Economist, http://www.economist.com/node/21545974

Easa, S., Hoel, L. (2008) Introduction (guest editorial), Computer-Aided Civil and Infrastructure Engineering, 23 (7), 481-482

Emerald (2008) ‘Emerald Journals 2009 pricelist', Publisher's webpages,

http://www.emeraldinsight.com/products/subs/pricelist 2009.xls?PHPSESSID=flogh5cbaco8 2i9h1b6p56uke7

European Commission (2006) 'Study on the Economic and Technical Evolution of the Scientific Publication Markets in Europe', European Commission, Directorate General for Research, Brussels, http://ec.europa.eu/research/science-society/pdf/scientific-publicationstudy en.pdf.

Gargouri, Y., Hajjem, C., Larivière, V., Gingras, Y., Carr, L., Brody, T., et al. (2010) 'SelfSelected or Mandated, Open Access Increases Citation Impact for Higher Quality Research', PLOS ONE 5(10): e13636. doi:10.1371/journal.pone.0013636.

Hindawi (2012) Statistics about the publishers journals, http://www.hindawi.com/statistics/

Howard, J. (2012) 'Legislation to Bar Public-Access Requirement on Federal Research Is Dead'. The Chronicle of Higher Education, 27 Febr 2012. http://chronicle.com/article/Legislation-to-Bar/130949/

ITC (2012) 'ITC Digital Library for construction IT research', http://itc.scix.net/

Laakso M, Welling P, Bukvova H, Nyman L., Björk B-C, Hedlund T. (2011) 'The Development of Open Access Journal Publishing from 1993 to 2009'. PLoS ONE 6(6): e20961. doi: 10.1371/journal.pone.0020961.

Less, T., Adeli, H. (2010) 'Computational Earthquake Engineering of Bridges', Scientia Iranica Transaction A - Civil Engineering, 17(5), 325-338

Lyons, C., Booth, A. (2011) 'An Overview of Access in the Fields of Business and Management' Journal of Business and Finance Librarianship, 16 (2), 108-124

OpenDOAR (2012) 'The Directory of Open Access Repositories', http://www.opendoar.org/

ROAR (2012) Registry of Open Access Repositories. http://roar.eprints.org/

ROARMAP (2012) Registry of Open Access Repository Material Archiving Policies, http://roarmap.eprints.org/ 
SCImago (2012), 'SCImago Journal \& Country Rank', http://www.scimagojr.com/

Sherpa/Juliet (2012) 'Research funders' open access policies'.http://www.sherpa.ac.uk/juliet/ Solomon, D., and Björk, B-C. (2012) 'A study of Open Access Journals using article processing charges', Accepted for publishing, Journal of the American Society for Information Science and Technology, OA copy available from www.openaccesspublishing.org/apc2/

Way, D. (2010) 'The Open Access Availability of Library and Information Science Literature', College \& Research Libraries, 71 (4), 302-309

http://crl.acrl.org/content/71/4/302.full.pdf+html

Sinha, K. (2004) 'Recent Changes in Journal Editorial Board', Journal of Transportation Engineering, 130 (3), 271

Ware, M., Mabe, M. (2009) 'The stm report - An overview of scientific and scholarly journals publishing', International Association of Scientific, Technical and Medical Publishers, http://www.stm-assoc.org/2009 1013 MWC STM Report.pdf 